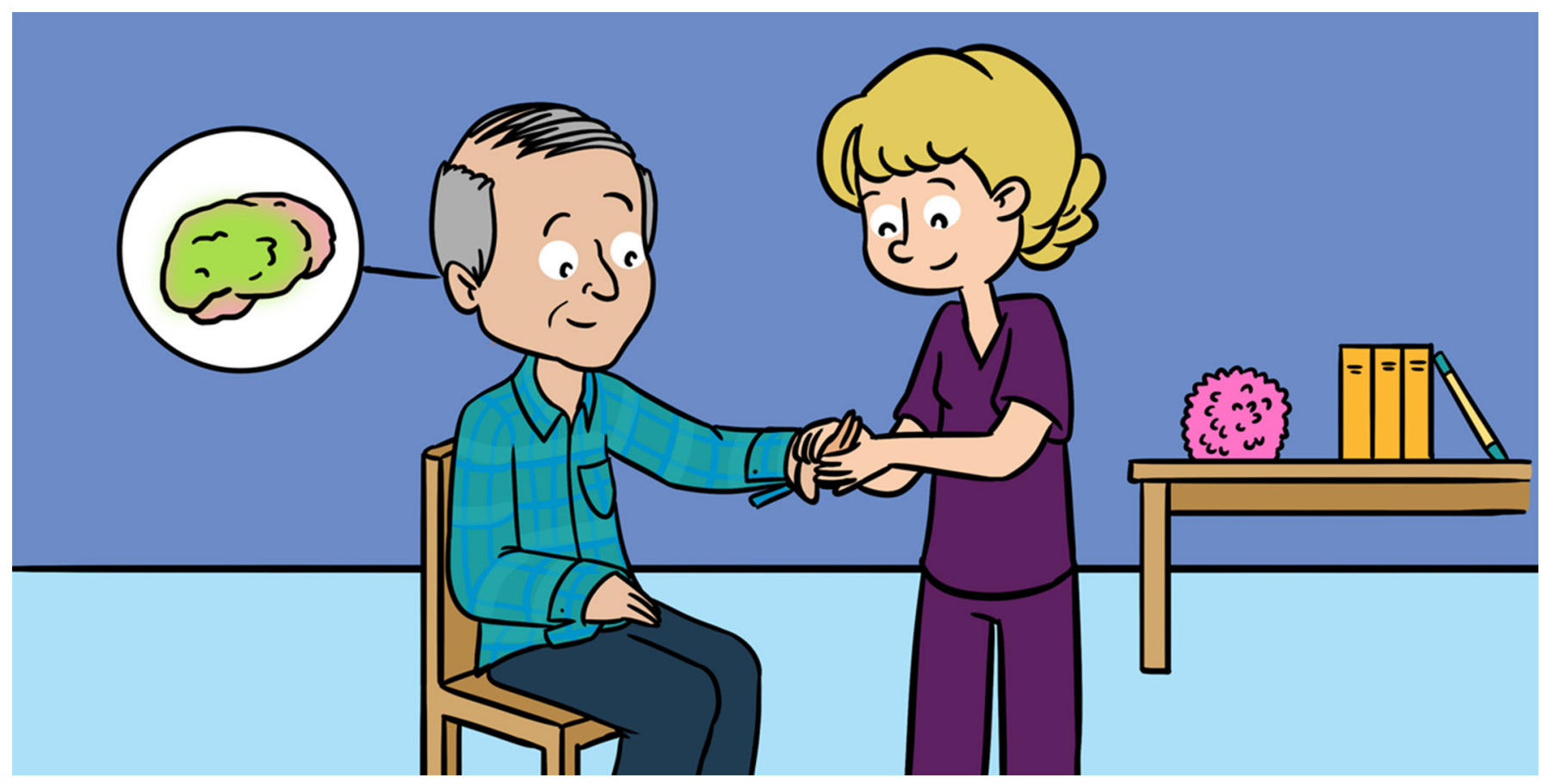

\title{
RECOVERY AFTER A STROKE-FIVE TIPS FOR REHABILITATION
}

\section{Alana B. McCambridge*}

Graduate School of Health, Discipline of Physiotherapy, University of Technology Sydney, Sydney, NSW, Australia

\section{YOUNG REVIEWER:}

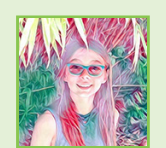

EDA

AGE: 11

\section{STROKE}

\section{When an area of the} brain is damaged from a lack of oxygen. Ischemic stroke is when there is a blockage, whereas hemorrhagic stroke is when there is a bleed in the brain.
Our brains are incredible. They allow us to speak, think, move, and so much more. The connections in our brains act as a complex network, more powerful than the best computer ever made. But what happens when a part of that network is damaged? What consequences will this have and how will the brain repair and recover? In this article, we explore a common brain injury-a stroke. We discuss how a stroke occurs, what impairments are caused by a stroke, and how the brain begins to repair and recover as best as possible. Lastly, we outline five key points that therapists keep in mind when they are helping a patient recover after a stroke.

\section{WHAT IS A STROKE?}

A stroke is when an area of the brain is starved of oxygen and brain cells in that area of the brain begin to die. There are two ways this can happen. The most common is through a blockage or a blood clot. This type of stroke is called an "ischemic" (pronounced "iss-skee-mick") stroke. 
Figure 1

There are two ways that a stroke can occur. The images on the left depict an ischemic stroke. The images on the right depict a hemorrhagic stroke. To better understand how a stroke occurs, the top images use a railway supplying food to a village as an analogy for the way blood vessels in the brain supply oxygen to the brain cells. Railway, blood vessel; train, red blood cell; food, oxygen; village, brain cells; boulder, blood clot

\section{BLOOD VESSEL}

Carries blood throughout the body. There are different types of blood vessels, such as arteries, which carry blood full of oxygen to the brain, or veins, which carry blood from the brain to the lungs to be reloaded with oxygen.

\section{Ischemic Stroke (Blockage)}
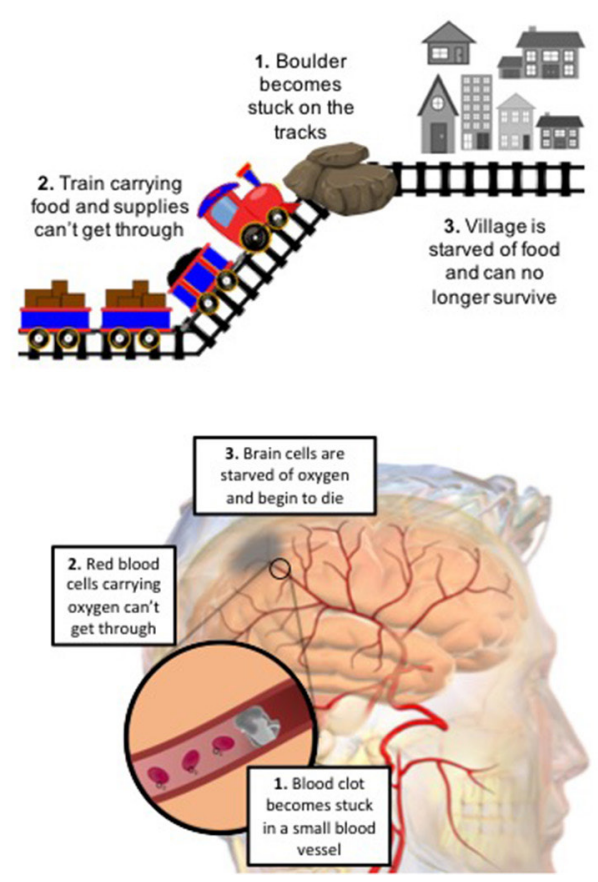

Hemorrhagic Stroke

(Bleed)
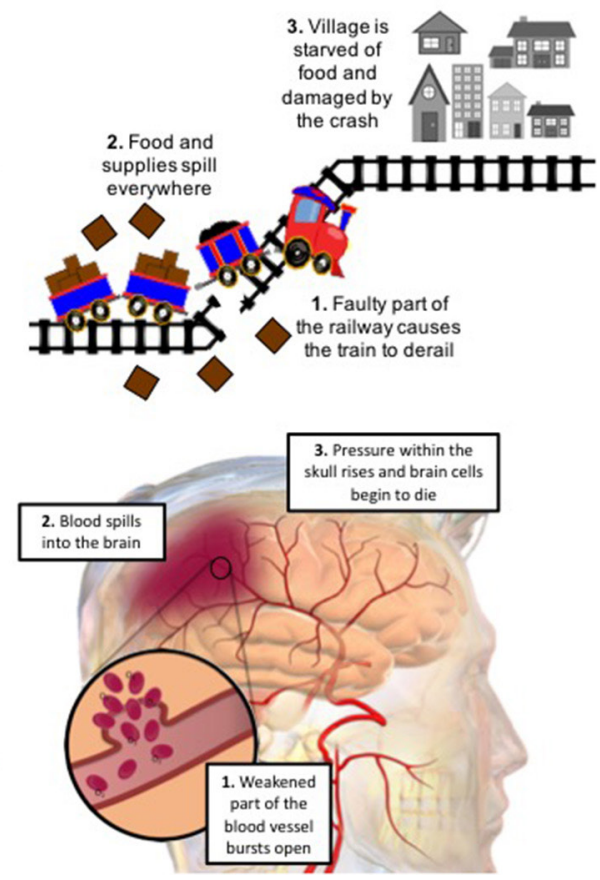

Figure 1

To better understand an ischemic stroke, let us imagine the blood vessels in your brain as a railway, supplying villages and towns with food to keep the people alive (see Figure 1 - Left). The trains that run on the railway carry loads of food to be delivered to the village, just as the blood vessels in the body carry oxygen to be delivered to the brain cells. An ischemic stroke occurs when a blood vessel (or railway) carrying oxygenated blood (food) becomes blocked by a clot (boulder), leaving the brain cells (or villages) that rely on oxygen from that blood vessel to slowly starve and die.

A "hemorrhagic" (pronounced "hem-or-adge-ick") stroke, or brain bleed, is the other type of stroke, and also the most life-threatening (see Figure 1 - Right). A hemorrhagic stroke occurs when a weak part of a blood vessel ruptures, causing blood to leak into the brain (like a faulty train track causing the train to derail and crash). As a consequence, areas of the brain are starved of oxygen as the leaked blood spills out into other areas of the brain. The leaked blood causes pressure to build up within the skull and brain, causing further damage to the brain cells.

\section{WHAT ARE THE CONSEQUENCES OF A STROKE?}

The symptoms of a stroke are varied and depend on which area of the brain is affected. As shown in Figure 2, the brain is organized into distinct areas that control specific functions. For that reason, when a stroke 
Figure 2

(A) View of the brain from the front. Here you can see the two sides (or hemispheres) of the brain. (B) The brain is organized into areas that control or support specific functions. In this image, can you find the motor cortex? The motor cortex controls movement and is located next to the "motor association area," which assists with planning to move. Can you find the visual cortex? The visual cortex controls vision and lets us interpret what we see with our eyes. The auditory cortex controls what we hear, which is next to the areas that control how we speak. There is also the frontal cortex at the front of the brain, which controls behavior and how we think or make decisions. Can you find the area that lets us interpret what we feel or touch? This area is called the sensory cortex. Images adapted from Blausen.com [1].

\section{A) View of the brain from the front}

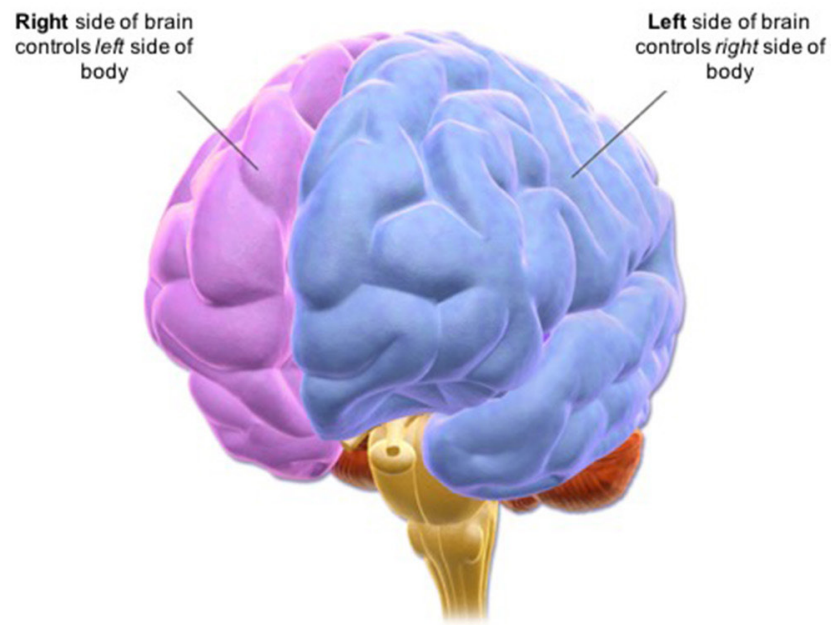

B) View of the left side of the brain

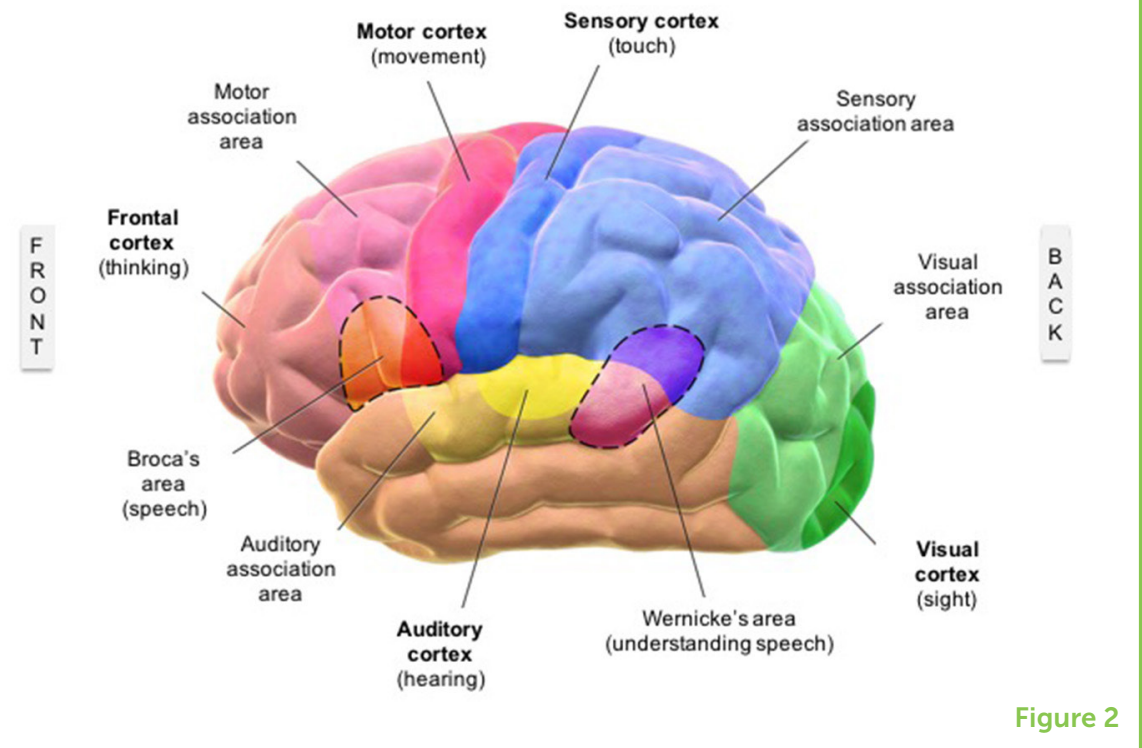

damages an area of the brain, the patient's symptoms are related to the function that was controlled by that area of the brain. For example, if the area of the brain that controls arm movement (also known as the motor cortex) is starved of oxygen by a stroke, then you would expect to see problems with the arm, such as weakness or even complete paralysis. Alternatively, if the area of the brain that controls vision (also known as the visual cortex) is affected by the stroke, then you would expect the patient to have vision problems.

Did you know that there are two sides to your brain (named the left and right hemispheres, see Figure 2A) and that each side of the brain controls the opposite side of the body? So, if there is damage to the motor area on the left side of the brain, then movement on the right side of the body would be impaired (see Figure 3A). Or, if the stroke damages the right visual cortex, then a person's ability to see to the left would be impaired (see Figure 3B). 
Figure 3

Two common impairments after a stroke are shown. In (A), a person with hemiparesis (half paralysis) has problems with his right arm, right leg, and the right side of his mouth. Given that the left side of the brain controls the right side of the body, can you tell which side of the brain the stroke occurred on? In (B), the vision of someone with hemianopia (half blindness) is shown. This person has lost the right half of their vision. Are you able to guess which side of the brain the stroke occurred on? In both cases, the stroke would have been on the left side of the brain, thereby causing impairments on the right side of the body.
A)

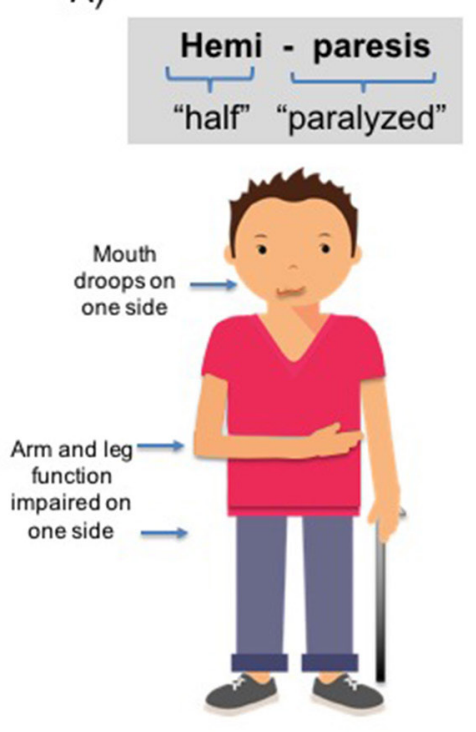

B)

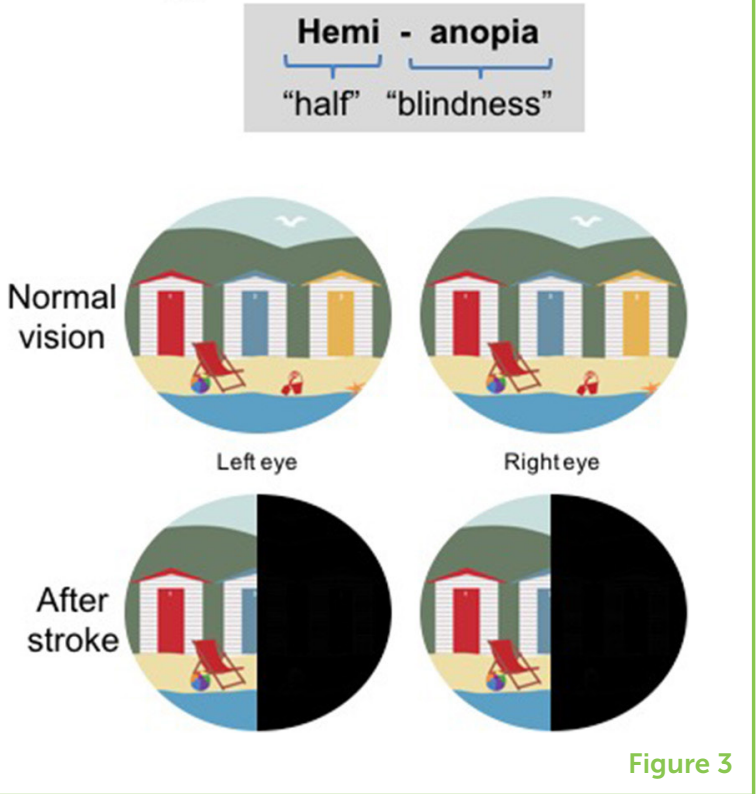

\section{WHAT TREATMENTS ARE AVAILABLE AFTER A STROKE?}

First, doctors must determine what kind of stroke has occurred. This is important because each type of stroke requires a different treatment. Using brain scanning devices, doctors must determine whether a bleed or a blockage is causing the patients symptoms.

If a blockage (ischemic stroke) is identified, the goal of treatment is to remove the blood clot. (That is why these treatments are called clotbusters!) Clot-busting medications are given to the patient to break down and dissolve the clot that is causing the blockage. Alternatively, surgery can be performed and a wire can be sent up into the blood vessel to pull the clot out.

If a bleed (hemorrhagic stroke) is identified, the goal for treatment is to stop the bleeding and reduce pressure building up within the skull. A bleed is most commonly treated using medications to reduce blood pressure and bleeding in the brain. In some cases, surgery may be required to drill a hole in the skull and release the pressure on the brain. Another surgery option is to place a clasp around the broken part of the blood vessel to clamp it shut and stop the bleeding.

Importantly, when a person is suspected of having a stroke, doctors must act quickly to return normal blood flow and normal pressure in the brain. The quicker that blood flow can return to normal, the better chance that more brain cells will be saved. 


\section{NEURON}

Specialized brain cell that computes and communicates information through its many connections. Neurons make connections with other neurons to form networks that control specific functions.

\section{NEUROPLASTICITY}

The ability of the brain to adapt and change.

\section{REHABILITATION}

Restoring a person's health through training and therapy.

\section{RECOVERY AFTER A STROKE}

In the days and weeks after a stroke, many biological processes in the brain begin to happen naturally or "spontaneously." These processes (1) repair neurons and other brain cells that were injured but did not die, and (2) clean up and remove brain cells that are dead.

The next step in the recovery process requires the brain to restructure and repair the damaged area. This important process is called neuroplasticity. Neuroplasticity is the ability of the brain to change, to learn, and to re-learn. Interestingly, scientists used to believe that neuroplasticity only occurred in babies as their brains developed throughout childhood. But now we know that the brain is continually changing throughout our entire lives. Neuroplasticity can occur by changing the connections between brain cells in the brain, such as improving the strength of a connection, increasing or decreasing the number of connections, or changing the function of a connection. In some cases, neuroplasticity may also involve the generation of new neurons (a process known as neurogenesis). However, more research is needed to find out how much neurogenesis contributes to stroke recovery.

\section{FIVE TIPS FOR ENHANCING NEUROPLASTICITY AND RECOVERY AFTER STROKE}

Neuroplasticity, or the ability of the brain to change, is the key principle that guides how therapists design and deliver rehabilitation programs for patients. Typically, the first goal of rehabilitation is to help the patients get back to the way they were before the stroke. Unfortunately this is not always possible, so for some stroke survivors, the goal of therapy is to find a new way of doing things.

Below are five important tips about neuroplasticity that therapists must consider when treating a patient (based on the article by Kleim and Jones [2]).

\section{Tip 1-“Use It or Lose It"}

A healthy brain maintains connections that are used frequently and "cleans away" connections that are not used for a period of time. Just like a muscle, if you do not use it enough the cells will weaken. Based on this rule, therapists encourage patients to keep moving the impaired limb to prevent connections in the brain from being lost. 


\section{Tip 2-“Use It and Improve It"}

When you perform a task and practice it over and over again, the same network of connections in the brain is activated over and over again. Repeated activation of that network causes it to be strengthened and work more efficiently, which ultimately leads to improved performance of the task. For example, when you practice playing an instrument, your performance gets better with practice as the network of connections in your brain that you use to play your instrument is strengthened. Therapists encourage patients to keep practicing their exercises and using their impaired side, as this will lead to positive changes in those specific brain networks.

\section{Tip 3-“Practice Specific"}

Rehabilitation exercises should be specific to the task or function that the patient wants to improve. If you want to change the area of the brain that controls the arm, you need to practice doing tasks with the arm. If you want to improve function of the left leg, do exercises with the left leg. If the patient is having problems with holding a fork, then the therapist will give specific exercises that mimic the position of the hand while it is holding a fork.

\section{Tip 4-“Practice Repeatedly"}

To enable the brain to change, many repetitions of a task need to be performed. For example, if you were learning how to juggle, would your ability to juggle be better if you practiced three times or if you practiced 30 times? The same is true for therapy after stroke, the more repetitions the better! Therapists encourage patients to practice repeatedly and continue practicing their exercises at home. The more repetitions the patient can practice each day, the quicker the brain will adapt and learn.

\section{Tip 5-“Practice Intensely"}

It is also important that when the patient practices, he or she practices intensely. This may be achieved by doing many repetitions or doing tasks that are challenging. Just like training for a long-distance race, you might start with short distances at first, but to get better, you have to push your muscles to work harder and run longer than you did before. This is the same in the brain. To encourage the networks in the brain to change, therapists challenge the patient to work harder and achieve a little more each time. 


\section{SUMMARY}

A stroke occurs when an area of the brain is starved of oxygen, caused by a blockage or a bleed in the brain. The after-effects of a stroke depend on which area of the brain was affected. Neuroplasticity is the process that allows the brain to recover from a stroke. Therapists design rehabilitation programs based on what is known about neuroplasticity, with the goal of returning the patient back to normal. The five tips explained above are essential principles for stroke rehabilitation.

\section{REFERENCES}

1. Blausen.com, S. 2014. Medical gallery of Blausen Medical 2014. WikiJ. Med. 1. doi: $10.15347 /$ wjm/2014.010

2. Kleim, J. A., and Jones, T. A. 2008. Principles of experience-dependent neural plasticity: implications for rehabilitation after brain damage. J. Speech. Lang. Hear. Res. 51:S225-39. doi: 10.1044/1092-4388(2008/018)

SUBMITTED: 11 July 2018; ACCEPTED: 29 January 2019;

PUBLISHED ONLINE: 19 February 2019.

EDITED BY: Leon Y. Deouell, Hebrew University of Jerusalem, Israel

CITATION: McCambridge AB (2019) Recovery After a Stroke-Five Tips for Rehabilitation. Front. Young Minds 7:21. doi: 10.3389/frym.2019.00021

CONFLICT OF INTEREST STATEMENT: The author declares that the research was conducted in the absence of any commercial or financial relationships that could be construed as a potential conflict of interest.

COPYRIGHT @ 2019 McCambridge. This is an open-access article distributed under the terms of the Creative Commons Attribution License (CC BY). The use, distribution or reproduction in other forums is permitted, provided the original author(s) and the copyright owner(s) are credited and that the original publication in this journal is cited, in accordance with accepted academic practice. No use, distribution or reproduction is permitted which does not comply with these terms.

\section{YOUNG REVIEWER}

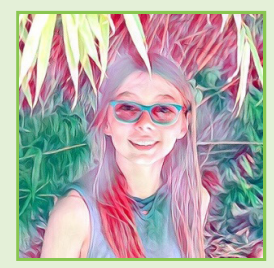

\section{EDA, AGE: 11}

I absolutely love science. Some of my other hobbies are drawing, reading, painting, and cooking. I also enjoy being on farms. My favorite thing to do on a farm is to pick apples. My favorite sport is basketball. I have been playing on the school basketball team for 2 years now. I enjoy participating in charity work. Last year my class had a tag sale and we used the money to send kids in low-income communities to summer camp. That is a little bit about me! 


\section{AUTHOR}

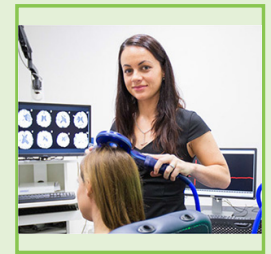

\section{ALANA B. MCCAMBRIDGE}

I am a Clinical Neuroscientist from the University of Technology Sydney in Australia. In my laboratory, I use noninvasive brain stimulation (as shown in the picture) to better understand how the motor areas of the brain change after a neurological injury or disease, and how these areas respond to different types of therapy. *alana.mccambridge@uts.edu.au 